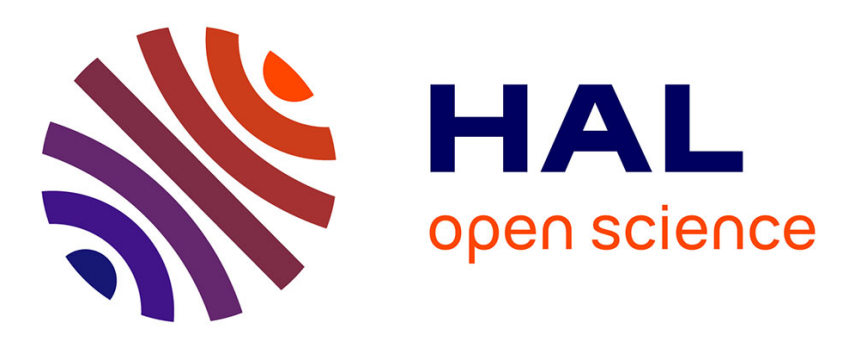

\title{
Sodium restriction modulates innate immunity and prevents cardiac remodeling in a rat model of metabolic syndrome
}

Bernard Jover, Christelle Reynes, Caroline Rugale, Cyril Reboul, Laura Jeanson, Michel Tournier, Anne Dominique Lajoix, Caroline Desmetz

\section{To cite this version:}

Bernard Jover, Christelle Reynes, Caroline Rugale, Cyril Reboul, Laura Jeanson, et al.. Sodium restriction modulates innate immunity and prevents cardiac remodeling in a rat model of metabolic syndrome. Biochimica et Biophysica Acta - Molecular Basis of Disease, 2017, 1863 (6), pp.1568-1574. 10.1016/j.bbadis.2017.02.026 . hal-01615219

\author{
HAL Id: hal-01615219 \\ https://hal.science/hal-01615219
}

Submitted on 2 May 2018

HAL is a multi-disciplinary open access archive for the deposit and dissemination of scientific research documents, whether they are published or not. The documents may come from teaching and research institutions in France or abroad, or from public or private research centers.
L'archive ouverte pluridisciplinaire HAL, est destinée au dépôt et à la diffusion de documents scientifiques de niveau recherche, publiés ou non, émanant des établissements d'enseignement et de recherche français ou étrangers, des laboratoires publics ou privés. 
SODIUM RESTRICTION MODULATES INNATE IMMUNITY AND PREVENTS

CARDIAC REMODELING IN A RAT MODEL OF METABOLIC SYNDROME

Bernard Jover $^{\mathrm{a}}$, Christelle Reynes ${ }^{\mathrm{b}, \mathrm{c}}$, Caroline Rugale ${ }^{\mathrm{d}}$, Cyril Reboul ${ }^{\mathrm{e}}$, Laura Jeanson ${ }^{\mathrm{d}}$, Michel Tournier $^{\mathrm{d}}$, Anne Dominique Lajoix ${ }^{\mathrm{d}}$, Caroline Desmetz $^{\mathrm{d}}$

a INSERM U1046, CNRS UMR 91214, Montpellier University, Montpellier, France.

${ }^{\mathrm{b}}$ Institute of Functional Genomics, CNRS UMR5203, INSERM U1191, Montpellier University, Montpellier, France.

${ }^{c}$ Laboratory of Biostatistics, Informatics and Pharmaceutical Physics, Montpellier University, Montpellier, France.

${ }^{\mathrm{d}}$ BioCommunication en CardioMétabolique $\left(\mathrm{BC}^{2} \mathrm{M}\right)$, Montpellier University, Montpellier France.

${ }^{\mathrm{e}}$ LaPEC EA4278, Avignon University, Avignon, France.

Short Title: Sodium, immunity, cardiac hypertrophy

Correspondence: $\quad$ Bernard Jover, INSERM U1046

IURC, 641 av doyen GIRAUD

34093 Montpellier Cedex 5

Phone: (33) 411759 926; Fax: (33) 411759547

E-mail: bernard.jover@inserm.fr 


\section{ABSTRACT}

In the view of the relationships between excessive sodium intake, immunity and target organ damage, we hypothesized that reduction in dietary sodium would be beneficial in the prevention of cardiac alterations through a restrained local immunity response in a rat model of metabolic syndrome. Sprague-Dawley rats were fed a $60 \%$ fructose diet with either a normal sodium $(0.64 \% \mathrm{NaCl})$ or a low sodium content $(<0.01 \% \mathrm{NaCl})$ for 8 weeks. After 4 weeks, rats were infused or not with angiotensin II $\left(200 \mathrm{ng} \cdot \mathrm{kg}^{-1} \cdot \mathrm{min}^{-1}, \mathrm{sc}\right)$ for 4 weeks. Tailcuff blood pressure was determined in conscious rats. Heart and left ventricle weight, cardiomyocyte size, and cardiac fibrosis were evaluated. We performed a transcriptomic analysis in order to identify differentially regulated cardiac mRNAs between normal and low sodium diets. We validated those results using qPCR and immunohistochemistry.

Angiotensin II-induced blood pressure rise was blunted $(\sim 50 \%)$ in the low-sodium fed rats while cardiac hypertrophy and fibrosis were prevented. Transcriptomic analysis revealed 66 differentially regulated genes including 13 downregulated genes under the low sodium diet and implicated in the innate immune response. This was confirmed by reduced cardiac macrophages infiltration under the low sodium diet.

Dietary sodium restriction prevents structural alterations of the heart of rats with fructoseinduced insulin resistance and angiotensin II-hypertension. The reduction of cardiac inflammation and macrophage infiltration suggests that innate immunity has an important role in the beneficial effect of sodium restriction on cardiac remodeling.

Key words: Low sodium diet, Cardiac Hypertrophy, Fibrosis, Innate Immunity, Macrophage, Inflammation. 


\section{INTRODUCTION}

The metabolic syndrome is defined as a cluster of hemodynamic and metabolic abnormalities $[1,2]$ associated with an increased risk for development of cardiovascular disease, and insulin resistance as a key factor $[3,4]$. Excessive dietary fructose consumption contributes to obesity in humans [5] and to insulin resistance in rodents [6]. In the rat model, a high fructose diet is associated with abnormal myocardial architecture [7] and cardiac hypertrophy [8] a preclinical disease strongly predictive of cardiovascular morbidity and mortality [9]. In humans [10], insulin resistance is associated with an increase in cardiac collagen content and diastolic dysfunction. Similar alterations are present in the heart of hypertensive patients [11] and rats [12]. In addition, enhanced angiotensin II and insulin resistance interact in the development of cardiovascular disease [13]. Reduction of left ventricular mass was reported to improve the risk of subsequent complications [14] and can be achieved with nonpharmacological maneuvers including a reduction in dietary sodium. Cardiac remodeling was obliterated by dietary sodium restriction in various models of hypertension $[15,16,17]$ as well as in hypertensive patients [18]. Moreover, the beneficial effect of sodium reduction on the heart was reported in insulin resistance [17] and in a new model of metabolic syndrome, the DahlS.Z-Lepr ${ }^{f a} /$ Lepr $^{f a}$ rat [19], an effect involving a reduction of oxidative stress [15,16,17].

In insulin resistance, inflammatory cells infiltrate the heart [20] and cardiac mRNA expression of inflammation factors are enhanced [21], and macrophages are a major source of proinflammatory cytokines, such as TNF- $\alpha$, IL-6 and IL1- $\beta$ [22]. In hypertension, inflammatory signals are released through monocytes and the recruitment of lymphocytes into cardiac tissue initiates the fibrosis cascade [10]. Adaptive immunity is also involved in cardiac remodeling, as demonstrated by the blunting of the deleterious effects of Angiotensin II (AngII)-induced hypertension in immune deficient RAG- $1^{-/-}$[23] and SCID [24] mice. We 
previously reported that sodium restriction reduced macrophage infiltration and the levels of TNF- $\alpha$ and IL-6 in the kidney and adipose tissue of the fructose fed rat [25]. Therefore, in insulin resistance as in hypertension, innate immunity participates in organ damage, and its modulation may explain the beneficial effect of the nutritional intervention. Yet, the implication of immunity deserves further investigation in the context of hypertension, insulin resistance and more widely of metabolic syndrome [26].

In the present study, we hypothesized that local innate immune response accompanies the beneficial effect of dietary sodium restriction on cardiac alterations in a rat model of metabolic syndrome that mimics the human situation [5]. Rats fed a high fructose diet were chronically infused with AngII to induce a clear hypertension, superimposed to insulin resistance. We performed a transcriptomic analysis on left ventricles to evaluate the influence of dietary sodium withdrawal.

\section{METHODS}

Full description of experimental procedures is available in Materials and Methods in the online-only Data Supplement. Two groups of 40 male Sprague-Dawley rats were fed for 8 weeks a $60 \%$ fructose diet with either a normal sodium (NS: $0.64 \% \mathrm{NaCl}$ ) or a low sodium content (LS: $<0.01 \% \mathrm{NaCl}$ ). After four weeks, twenty rats from each regimen were infused subcutaneously with angiotensin II (AngII, $200 \mathrm{ng} \cdot \mathrm{kg}^{-1} \cdot \mathrm{min}^{-1}$ ) for the remaining four weeks. The statistical evaluation was performed using two-factor analysis of variance (ANOVA) and post hoc comparisons were performed by means of Fisher's Protected Least Significant Differences (PLSD) test. If the data were not normally distributed, statistical evaluation was 
performed by using ANOVA (Kruskall-Wallis) and Mann-Whitney U test. Differences were considered significant when $\mathrm{p}<0.05$.

For transcriptomic analysis, statistical analysis was performed using R software version 3.3.0 along with the Limma package. The method used for background correction was based on the normal-exponential convolution model with the saddle-point approximation to maximum likelihood. Normalization was performed using cyclic loess method. Only probes whose signal was considered as higher than background in at least four out of six replicates in at least one condition were selected for further analysis. Within-array replicate probes were replaced with their average. The assessment of differentially expressed mRNAs between NS diet and LS diet was performed using the Limma GLM (Generalized Linear Model) method followed by Benjamini Hochberg correction for multiple testing. Genes with a corrected p-value lower than 0.1 were selected for further investigation.

\section{RESULTS}

\section{$\underline{3.1 \text { Low sodium diet influences metabolic parameters }}$}

After four weeks of fructose regimen, i.e. before AngII infusion, body weight was significantly lower in rats submitted to dietary sodium restriction $(\mathrm{p}=0.0003)$. This effect of low sodium persisted during the four next weeks on AngII infusion. Yet, body weight gain and final body weight were similar between hypertensive and normotensive rats on the same diet (Table 1). Food intake was significantly lower (by 10-12\%) in both LS groups compared to control NS groups (Table 1). Fasting plasma glucose was not significantly different between groups (Table 1). The response to insulin injection induced a large fall in blood glucose in all rats. However, plasma glucose and AUC decreased to a larger extent in control LS fructose rats compared to the three other groups, which were not different from each other (Supplementary data, Figure S1). 


\section{$\underline{\text { 3.2 Low sodium diet influences cardiovascular parameters }}$}

Before AngII-infusion, i.e. after 4 weeks on the fructose diet, systolic tail-cuff pressure was similar in rats on the NS and LS diet (Figure 1A). As expected, AngII led to an important rise in blood pressure that was significantly reduced in the LS compared to the NS fed group (Figure 1B, percent change of $22 \pm 3$ vs $41 \pm 4 \%$, respectively).

\subsection{Cardiac morphological and histological alterations are prevented by low sodium diet.}

As expected, heart weight and left ventricle weight as well as HW index (HWI) and left ventricle weight index were significantly higher in rats infused with AngII (Table 1). Yet, the effect of AngII was significantly less marked in LS rats (5-6\% increase) compared to rats on NS diet (18-24\%). Similarly, cardiomyocyte size was significantly smaller in AngII-infused, LS fructose rats compared to their NS counterparts (Figure 1C). When the linear relationship between body weight and heart weight was examined, the steepening of the slope in AngII, NS fructose rats was prevented in LS rats (Figure 1D).

Sirius red area staining of cardiac tissue was not significantly different in LS vs. NS fructose control groups $(4.8 \pm 0.9$ vs $3.9 \pm 0.7 \%$, Figure $1 \mathrm{E})$. AngII infusion was associated with a larger stained area in rats fed the NS but not LS diet $(6.5 \pm 1.2$ vs $4.97 \pm 0.8 \%)$. Cardiac mRNA expression of TGF- $\beta$ and SMAD2 were significantly reduced in LS Fructose rats compared to the respective NS Fructose rats infused or not with AngII (Figure 1F).

\section{$\underline{3.4}$ Transcriptomic analysis of cardiac tissue from NS and LS rats}

To identify genes involved in the prevention of cardiac alterations under the LS diet, we compared transcriptomes based on the sodium criteria, i.e. from LS and NS ( $n=6$ in each) left ventricles using microarrays. Following data processing and statistical analysis, we obtained a 
list of 66 transcripts differentially regulated (21 upregulated, 45 downregulated) between NS and LS rats. We subjected this list to Gene Ontology (GO) classification and enrichment analysis, which describes genes in terms of their associated biological processes, molecular function and cellular component. In figure 2, we show the classification in terms of biological process with fold enrichment when significant. Genes implicated in localization, transport, development process, immune system process, adhesion, vesicle-mediated transport, morphogenesis, exocytosis, regulation of liquid surface tension, vasoconstriction, were significantly enriched.

Although other genes within the 66 up- or down-regulated could be of interest, we focused on genes belonging to the immune system process. GO analysis classified 11 genes in the immune system process, which represented a significant fold enrichment of 2.38 with a $\mathrm{p}$ value of 0.0059 . After reviewing the literature, 3 candidate genes were not retained for further analysis (Cd248, Col4a1 and Lphn1) and 5 genes were added to the list as they appeared relevant to the immune system process (C1qtnf6, C1qtnf9, Hamp, Fcgr3, Tlr2). These final 13 genes are shown in table 2 and box plot representing microarrays results for each gene are shown in figure S2. Interestingly, all transcripts were downregulated upon LS diet.

\section{$\underline{3.5 \text { Validation of expression variations by } \mathrm{qPCR} \text { and western blotting }}$}

Overall, there was a good correlation $\left(r^{2}=0.73\right)$ between the expression levels detected with microarrays and quantitative PCR (Table 2 and data not shown). On the 13 targets evaluated, all but 3 (Tlr2, C1qtnf6 and Tpo) were confirmed by qPCR regarding the direction of change (downregulation) and statistical significance $(\mathrm{p}<0.05)$. Quantitative PCR analysis also confirmed low range expression variations, varying between -1.17 (Fes) and -2.86 (Hamp). Altogether these results show a global downregulation of these immune transcripts linked to 
cardiac protection induced by salt restriction. The lower expression of Aif1, S100a11 and Hamp was also validated at the protein level by immunoblot (Figure S3).

\section{$\underline{\text { 3.6 Macrophage infiltration into cardiac tissue is prevented by the LS diet }}$}

To confirm microarrays and qPCR results at a functional level, we performed immunohistochemistry on left ventricles from the 4 groups of rats. Macrophage infiltration, as evidenced by CD68-positive cells, was enhanced in NS Fructose animals infused with AngII compared with control NS Fructose rats. Interestingly, macrophage infiltration was prevented in LS Fructose rats in both control and AngII-infused groups (Figure 3A). Moreover, cardiac mRNA expression of CD68 and CD11b, two additional macrophages markers, were significantly reduced in control and AngII-infused rats fed the LS diet (Figure 3B). This was correlated with reduced expression of EMR1 in LS rats (Table 2). We also evaluated cardiac expression of the inflammatory related genes CCL2 (MCP1), a transcript coding for a C-C chemokine involved in macrophage tissue recruitment in inflammatory sites, and its cell surface receptor, CCR2. Cardiac expression of CCR2 was unmodified by sodium restriction, whereas CCL2 expression was significantly reduced in rats fed with LS diet (Figure 3C). Similarly, TNF- $\alpha$ and RELA expressions were lower in the heart of LS rats (Figure 3C)

\section{DISCUSSION}

In the present study, dietary sodium restriction prevents structural alterations of the heart of rats with combined insulin resistance and hypertension. We previously reported that reduction of dietary salt was able to prevent cardiac hypertrophy in AngII-hypertension [27] as well as in insulin resistance associated with high fructose feeding [17]. Reduction of cardiac mass may be related to the concomitant lowering of body growth occurring during low sodium feeding. In our previous study in fructose-fed rats [17], the effect of low sodium diet was 
clearer on the slope of the relationship between body and heart weight. In the current experiments, the steepening of the slope induced by AngII was totally prevented by sodium withdrawal. Therefore, body weight difference and body growth had probably only a minor influence on the prevention of cardiac hypertrophy. Blunting of hypertension may also explain the effect of low sodium diet on cardiac mass. However, the cardiac hypertrophy appeared to be independent of afterload in this animal model [28], suggesting that other mechanisms have a preeminent role in cardiac protection.

Associated with hypertrophy, fibrosis is another structural alteration of cardiac tissue in insulin resistance [8] and hypertension [29]. Dietary sodium restriction had a preventive effect on cardiac fibrosis associated with AngII infusion, while no obvious effect was detected in control normotensive fructose rats. Among the signals that promote fibrosis, TGF- $\beta$ has a pivotal role by activating myofibroblasts and producing collagen [30] and particularly collagen type I alpha 2 (COL1A2) [31]. Despite their lack of increase after four weeks of AngII infusion in normal sodium fructose fed rats, TGF- $\beta$ and SMAD2 may have been stimulated transiently during the initial phase of angiotensin II administration. An important finding of our transcriptomic analysis is that COL1A2 is downregulated in the heart of rats under low salt diet. This agrees with a study showing that a high salt diet in a mouse model of normotensive DOCA induced cardiac hypertrophy along with overexpression of COL1A2 compared with the low salt diet [32]. To extend our transcriptomic analysis, we explored the expression of several genes involved in the inflammation process. Low sodium diet was associated with a downregulation of TNF- $\alpha$ and RELA, the p65 subunit of NFkB, which regulates the expression of several genes implicated in inflammation. The TNF pathway is a known negative regulator of COL1A2 expression, thus being antagonistic to TGF- $\beta$ effects [33]. The fact that these pro- and anti-fibrotic cytokines are reduced by LS diet while a global 
downregulation of COL1A2 and a lower fibrosis are observed suggest a predominant effect of TGF- $\beta$ over TNF- $\alpha$ in the context of a cardiometabolic disease. Altogether, these observations favor a modulation by dietary sodium intake of the TGF- $\beta$ /SMAD signaling pathway, regulating collagen production in the heart.

A major finding of this study is the downregulation of innate immunity related genes in the cardiac tissue of fructose rats when sodium was excluded from the diet. Transcriptomic analysis comparing LS and NS diets revealed differential regulation of 13 genes, several of them being involved in the so called "sterile inflammation", a mechanism allowing sensing and reacting to non-microbial signals, through host receptors and endogenous molecules (DAMPs, Damage Associated Molecular Patterns) [34]. S100 calcium-binding proteins have been identified as DAMPs based on their ability to stimulate pro-inflammatory cytokine production. Particularly, S100A11 was found in normal cardiomyocytes, and its tissular expression was enhanced with myocardial damage [35]. S100A11 is a ligand of RAGE, the receptor for advanced glycation end products, and was shown to stimulate inflammation induced chondrocyte hypertrophy [36]. Moreover, RAGE is expressed on macrophages, and cardiac fibroblasts [37]. Here, both S100A11 and RAGE (Table 2 and Figure S3-S4) are downregulated in the heart of rats on low sodium diet, as simultaneously observed for TNF- $\alpha$ and RELA. Thus, S100A11 and its receptor RAGE could be implicated in sensing myocardial damage induced by high fructose and AngII, and their downregulation may be a mechanism through which low sodium diet prevents cardiac inflammation and damages.

Three downregulated transcripts, hepcidin (HAMP), allograft inflammatory factor (AIF)-1 and the tyrosine kinase FES, retained our attention because they are related to the innate immune receptors TLR2 and TLR4 (Toll Like Receptors), which are, along with RAGE, DAMPS receptors [34]. Hepcidin is an antimicrobial peptide induced in macrophages during 
inflammation. Hepcidin expression is induced following TLR2 and TLR4 activation in macrophages [38] and elevated levels were found in peripheral mononuclear cells from patients with diabetes and obesity [39]. Therefore, hepcidin can also be induced in chronic inflammatory states and represent another component of the innate immune response downregulated by LS diet.

Allograph inflammatory factor is another immune-related gene that is downregulated in low sodium fed rats (Table 2, Figure S3). AIF1 was first identified in injured rat carotid arteries [40], and expressed by activated macrophages [41]. Its expression is reduced under antiinflammatory conditions in several models [42] and overexpressed in patients with cardiac allograft rejection [43]. Moreover, AIF1 was proposed as a significant predictor of activated macrophages in metabolic and cardiovascular diseases in humans [44]. AIF1 can be induced by TNF- $\alpha$, and in turn, induces CCL2 expression and chemotaxis of peripheral blood mononuclear cells [45]. We believe this is the first time AIF1 is found to be downregulated in cardiac tissue in a hypertensive and insulin resistant rat model under a salt restrictive diet.

The third transcript of interest is FES/FPS, a cytoplasmic tyrosine kinase involved in the regulation of innate immunity and inflammation. It acts by internalization and downregulation of the TLR4 receptor complex, leading to a reduced TNF- $\alpha$ secretion in macrophages via NFkB lowering as reported in Fes-/- mice [46]. Although the present observation of a downregulation of FES/FPS in LS rats may be surprising, it probably reflects a complex inflammation process where there is an imbalance between pro- and anti-inflammatory signals. Altogether, our results clearly demonstrate that salt restriction reduces cardiac damage in metabolic syndrome and suggest that the nutritional manoeuvre acts through the inhibition of innate immunity as proposed in Figure S6.

Along with TLR2, RAGE and TLR4 are major putative sensors of DAMPs [34], and hence we investigated their mRNA expression in our model. TLR2, TLR4 and RAGE expression 
were unmodified by salt restriction. In the AngII infused rat, an upregulation of TNF- $\alpha$ and TLR2 mRNAs was observed in the kidney and of TLR4 and TNF- $\alpha$ in rat vascular smooth muscle cells [47]. We observe no change in TLR2 and TLR4 mRNA expression in left ventricles in our model (Table 2 and Figure S5, qPCR data); however, genes interacting with these receptors were all found downregulated by salt restriction, therefore much likely inhibiting related pathways.

The transcriptomic data, confirmed with qPCR analysis and IHC, indicate that sodium withdrawal from the diet was associated with a lower recruitment of CD68 macrophages in cardiac tissue of fructose-fed rats. This was accompanied with a significant reduction of inflammatory genes, such as TNF- $\alpha$, RELA, and the chemokine CCL2, the latter allowing macrophage recruitment. A comparable effect was observed in the Dahl salt-sensitive/obese rat [19]. In the present study, the anti-inflammatory influence of sodium restriction was obtained in presence of two pro-inflammatory maneuvers, a nutritional (fructose feeding) and a hormonal (AngII) chronic exposure. In our previous study [25], fructose feeding was associated with a greater macrophage infiltration in the kidney and abdominal adipose tissue, an effect blunted by the LS diet. In the heart, a low grade inflammation was also observed in high-carbohydrate, high-fat fed rats [20]. On the other hand, monocytes/macrophages infiltration and inflammation have a role in the development of AngII mediated vascular injury [48]. In the heart, AngII induced fibrosis through CCL2 and subsequent monocytes recruitment [49], and its hypertrophic effect was significantly attenuated in TNF- $\alpha$ deficient mice [50]. Together with our present findings, these observations strongly suggest that reduction of macrophage recruitment and cardiac inflammation have an important role in the beneficial effect of sodium restriction on cardiac remodeling. Our work shows that a simple 
diet modification consisting in sodium reduction results in declined cardiac macrophage infiltration and consequent improvement of hypertension and cardiac damage.

\section{CONCLUSIONS}

Our data support the concept that innate immunity participates in the development of cardiac remodeling in metabolic syndrome. These findings support the rationale for further clinical studies to evaluate the potential benefit of dietary sodium reduction in patients with cardiac hypertrophy associated or not with insulin resistance and hypertension. Moreover, it will be important to determine whether changes in sodium consumption are associated with inflammatory and immune responses in this context. 


\section{ACKNOWLEDGMENTS}

We acknowledge Caroline Guzman and Valérie Rodrigues for their expert technical assistance.

The authors would like to dedicate this work to the memory of Pr. Albert Mimran, past president of the Société Française d'Hypertension Artérielle and of the International Society of Hypertension, who died on the 29th of November 2016.

\section{SOURCE OF FUNDINGS}

This research was supported by La Fondation de Recherche sur l'Hypertension Artérielle and by the Ministère de l'Education Nationale de l'Enseignement Supérieur et de la Recherche.

\section{DISCLOSURE}

The authors have no interest to disclose 


\section{REFERENCES}

[1]. Reaven GM. Banting lecture 1988. Role of insulin resistance in human disease. Diabetes. 1988;37(12):1595-1607.

[2]. Lakka H-M, Laaksonen DE, Lakka TA, et al. The metabolic syndrome and total and cardiovascular disease mortality in middle-aged men. JAMA. 2002;288(21):2709-2716.

[3]. Morris AD, Connell JM. Insulin resistance and essential hypertension: mechanisms and clinical implications. Am J Med Sci. 1994;307 Suppl 1:S47-52.

[4]. Nakamura M, Yamazaki O, Shirai A, et al. Preserved Na/HCO3 cotransporter sensitivity to insulin may promote hypertension in metabolic syndrome. Kidney Int. 2015;87(3):535-542. doi:10.1038/ki.2014.351.

[5]. Elliott SS, Keim NL, Stern JS, Teff K, Havel PJ. Fructose, weight gain, and the insulin resistance syndrome. Am J Clin Nutr. 2002;76(5):911-922.

[6]. Zavaroni I, Sander S, Scott S, Reaven GM. Effect of fructose feeding on insulin secretion and insulin action in the rat. Metabolism. 1980;29(10):970-973.

[7]. Cheng S-M, Cheng Y-J, Wu L-Y, et al. Activated apoptotic and anti-survival effects on rat hearts with fructose induced metabolic syndrome. Cell Biochem Funct. 2014;32(2):133141. doi:10.1002/cbf.2982.

[8]. Delbosc S, Paizanis E, Magous R, et al. Involvement of oxidative stress and NADPH oxidase activation in the development of cardiovascular complications in a model of insulin resistance, the fructose-fed rat. Atherosclerosis. 2005;179(1):43-49. doi:10.1016/j.atherosclerosis.2004.10.018.

[9]. Devereux RB, Alderman MH. Role of preclinical cardiovascular disease in the evolution from risk factor exposure to development of morbid events. Circulation. 1993;88(4 Pt 1):1444-1455.

[10]. Wynn TA. Common and unique mechanisms regulate fibrosis in various fibroproliferative diseases. J Clin Invest. 2007;117(3):524-529. doi:10.1172/JCI31487. [11]. González A, López B, Querejeta R, Zubillaga E, Echeverría T, Díez J. Filling pressures and collagen metabolism in hypertensive patients with heart failure and normal ejection fraction. Hypertens Dallas Tex 1979. 2010;55(6):1418-1424. doi:10.1161/HYPERTENSIONAHA.109.149112.

[12]. Kuwahara F, Kai H, Tokuda K, et al. Hypertensive Myocardial Fibrosis and Diastolic Dysfunction: Another Model of Inflammation? Hypertension. 2004;43(4):739-745. doi:10.1161/01.HYP.0000118584.33350.7d. 
[13]. Zhou M-S, Schulman IH, Zeng Q. Link between the renin-angiotensin system and insulin resistance: implications for cardiovascular disease. Vasc Med Lond Engl. 2012;17(5):330-341. doi:10.1177/1358863X12450094.

[14]. Verdecchia P, Angeli F, Borgioni C, et al. Changes in cardiovascular risk by reduction of left ventricular mass in hypertension: a meta-analysis. Am J Hypertens. 2003;16(11 Pt 1):895-899.

[15]. de Simone G, Devereux RB, Camargo MJ, Wallerson DC, Laragh JH. Influence of sodium intake on in vivo left ventricular anatomy in experimental renovascular hypertension. Am J Physiol. 1993;264(6 Pt 2):H2103-2110.

[16]. Wilczynski EA, Yuan B, Leenen FH. Dietary sodium restriction and the development of two-kidney, one-clip hypertension in young versus adult rats. Can J Physiol Pharmacol. 1992;70(4):452-457.

[17]. Rugale C, Oudot C, Desmetz C, Guzman C, Lajoix A, Jover B. Sodium restriction prevents cardiovascular remodeling associated with insulin-resistance in the rat. Ann Cardiol Angéiologie. 2013;62(3):139-143. doi:10.1016/j.ancard.2013.03.001.

[18]. Jula AM, Karanko HM. Effects on left ventricular hypertrophy of long-term nonpharmacological treatment with sodium restriction in mild-to-moderate essential hypertension. Circulation. 1994;89(3):1023-1031.

[19]. Hattori T, Murase T, Takatsu M, et al. Dietary salt restriction improves cardiac and adipose tissue pathology independently of obesity in a rat model of metabolic syndrome. $J \mathrm{Am}$ Heart Assoc. 2014;3(6):e001312. doi:10.1161/JAHA.114.001312.

[20]. Poudyal H, Panchal SK, Ward LC, Waanders J, Brown L. Chronic high-carbohydrate, high-fat feeding in rats induces reversible metabolic, cardiovascular, and liver changes. Am J Physiol Endocrinol Metab. 2012;302(12):E1472-1482. doi:10.1152/ajpendo.00102.2012.

[21]. Qin B, Polansky MM, Harry D, Anderson RA. Green tea polyphenols improve cardiac muscle mRNA and protein levels of signal pathways related to insulin and lipid metabolism and inflammation in insulin-resistant rats. Mol Nutr Food Res. 2010;54 Suppl 1:S14-23. doi:10.1002/mnfr.200900306.

[22]. Patel PS, Buras ED, Balasubramanyam A. The role of the immune system in obesity and insulin resistance. J Obes. 2013;2013:616193. doi:10.1155/2013/616193.

[23]. Guzik TJ, Hoch NE, Brown KA, et al. Role of the $\mathrm{T}$ cell in the genesis of angiotensin II induced hypertension and vascular dysfunction. J Exp Med. 2007;204(10):2449-2460. doi:10.1084/jem.20070657. 
[24]. Crowley SD, Song Y-S, Lin EE, Griffiths R, Kim H-S, Ruiz P. Lymphocyte responses exacerbate angiotensin II-dependent hypertension. Am J Physiol Regul Integr Comp Physiol. 2010;298(4):R1089-1097. doi:10.1152/ajpregu.00373.2009.

[25]. Oudot C, Lajoix AD, Jover B, Rugale C. Dietary sodium restriction prevents kidney damage in high fructose-fed rats. Kidney Int. 2013;83(4):674-683. doi:10.1038/ki.2012.478. [26]. McCarthy CG, Goulopoulou S, Wenceslau CF, Spitler K, Matsumoto T, Webb RC. Toll-like receptors and damage-associated molecular patterns: novel links between inflammation and hypertension. Am J Physiol Heart Circ Physiol. 2014;306(2):H184-196. doi:10.1152/ajpheart.00328.2013.

[27]. Rugale C, Delbosc S, Cristol J-P, Mimran A, Jover B. Sodium restriction prevents cardiac hypertrophy and oxidative stress in angiotensin II hypertension. Am J Physiol Heart Circ Physiol. 2003;284(5):H1744-1750. doi:10.1152/ajpheart.00864.2002.

[28]. Dostal DE, Baker KM. Angiotensin II stimulation of left ventricular hypertrophy in adult rat heart: mediation by the AT1 receptor. Am J Hypertens. 1992,5:276-280.

[29]. Conrad CH, Brooks WW, Hayes JA, Sen S, Robinson KG, Bing OH. Myocardial fibrosis and stiffness with hypertrophy and heart failure in the spontaneously hypertensive rat. Circulation. 1995;91(1):161-170.

[30]. Petrov VV, Fagard RH, Lijnen PJ. Transforming growth factor-beta(1) induces angiotensin-converting enzyme synthesis in rat cardiac fibroblasts during their differentiation to myofibroblasts. J Renin-Angiotensin-Aldosterone Syst JRAAS. 2000;1(4):342-352. doi:10.3317/jraas.2000.064.

[31]. Inagaki Y, Truter S, Ramirez F. Transforming growth factor-beta stimulates alpha 2(I) collagen gene expression through a cis-acting element that contains an Sp1-binding site. $J$ Biol Chem. 1994;269(20):14828-14834.

[32]. Wang Q, Domenighetti AA, Schäfer SC, et al. Impact of salt on cardiac differential gene expression and coronary lesion in normotensive mineralocorticoid-treated mice. Am $J$ Physiol Regul Integr Comp Physiol. 2012;302(9):R1025-1033. doi:10.1152/ajpregu.00387.2011.

[33]. Kähäri VM, Chen YQ, Su MW, Ramirez F, Uitto J. Tumor necrosis factor-alpha and interferon-gamma suppress the activation of human type I collagen gene expression by transforming growth factor-beta 1. Evidence for two distinct mechanisms of inhibition at the transcriptional and posttranscriptional levels. J Clin Invest. 1990;86(5):1489-1495. doi:10.1172/JCI114866. 
[34]. Chen GY, Nuñez G. Sterile inflammation: sensing and reacting to damage. Nat Rev Immunol. 2010;10(12):826-837. doi:10.1038/nri2873.

[35]. Inamoto S, Murao S, Yokoyama M, Kitazawa S, Maeda S. Isoproterenol-induced myocardial injury resulting in altered S100A4 and S100A11 protein expression in the rat. Pathol Int. 2000;50(6):480-485.

[36]. Donato R. RAGE: a single receptor for several ligands and different cellular responses: the case of certain S100 proteins. Curr Mol Med. 2007;7(8):711-724.

[37]. Turner NA. Inflammatory and fibrotic responses of cardiac fibroblasts to myocardial damage associated molecular patterns (DAMPs). J Mol Cell Cardiol. 2016;94:189-200. doi:10.1016/j.yjmcc.2015.11.002.

[38]. Layoun A, Santos MM. Bacterial cell wall constituents induce hepcidin expression in macrophages through MyD88 signaling. Inflammation. 2012;35(4):1500-1506. doi:10.1007/s10753-012-9463-4.

[39]. Andrews M, Soto N, Arredondo-Olguín M. Association between ferritin and hepcidin levels and inflammatory status in patients with type 2 diabetes mellitus and obesity. Nutr Burbank Los Angel Cty Calif. 2015;31(1):51-57. doi:10.1016/j.nut.2014.04.019. [40]. Autieri MV. cDNA cloning of human allograft inflammatory factor-1: tissue distribution, cytokine induction, and mRNA expression in injured rat carotid arteries. Biochem Biophys Res Commun. 1996;228(1):29-37. doi:10.1006/bbrc.1996.1612.

[41]. Chen ZW, Ahren B, Ostenson CG, et al. Identification, isolation, and characterization of daintain (allograft inflammatory factor 1), a macrophage polypeptide with effects on insulin secretion and abundantly present in the pancreas of prediabetic BB rats. Proc Natl Acad Sci U S A. 1997;94(25):13879-13884.

[42]. Zhao Y-Y, Yan D-J, Chen Z-W. Role of AIF-1 in the regulation of inflammatory activation and diverse disease processes. Cell Immunol. 2013;284(1-2):75-83. doi:10.1016/j.cellimm.2013.07.008.

[43]. McDaniel DO, Zhou X, Moore CK, Aru G. Cardiac allograft rejection correlates with increased expressions of Toll-like receptors 2 and 4 and allograft inflammatory factor 1. Transplant Proc. 2010;42(10):4235-4237. doi:10.1016/j.transproceed.2010.09.091. [44]. Fukui M, Tanaka M, Toda H, et al. The serum concentration of allograft inflammatory factor-1 is correlated with metabolic parameters in healthy subjects. Metabolism. 2012;61(7):1021-1025. doi:10.1016/j.metabol.2011.12.001.

[45]. Kadoya M, Yamamoto A, Hamaguchi M, et al. Allograft inflammatory factor-1 stimulates chemokine production and induces chemotaxis in human peripheral blood 
mononuclear cells. Biochem Biophys Res Commun. 2014;448(3):287-291.

doi:10.1016/j.bbrc.2014.04.106.

[46]. Parsons SA, Greer PA. The Fps/Fes kinase regulates the inflammatory response to endotoxin through down-regulation of TLR4, NF-kappaB activation, and TNF-alpha secretion in macrophages. J Leukoc Biol. 2006;80(6):1522-1528. doi:10.1189/jlb.0506350.

[47]. Singh MV, Abboud FM. Toll-like receptors and hypertension. Am J Physiol Regul Integr Comp Physiol. 2014;307(5):R501-504. doi:10.1152/ajpregu.00194.2014.

[48]. De Ciuceis C, Amiri F, Brassard P, Endemann DH, Touyz RM, Schiffrin EL. Reduced vascular remodeling, endothelial dysfunction, and oxidative stress in resistance arteries of angiotensin II-infused macrophage colony-stimulating factor-deficient mice: evidence for a role in inflammation in angiotensin-induced vascular injury. Arterioscler Thromb Vasc Biol. 2005;25(10):2106-2113. doi:10.1161/01.ATV.0000181743.28028.57.

[49]. Haudek SB, Cheng J, Du J, et al. Monocytic fibroblast precursors mediate fibrosis in angiotensin-II-induced cardiac hypertrophy. J Mol Cell Cardiol. 2010;49(3):499-507. doi:10.1016/j.yjmcc.2010.05.005.

[50]. Sriramula S, Haque M, Majid DSA, Francis J. Involvement of tumor necrosis factoralpha in angiotensin II-mediated effects on salt appetite, hypertension, and cardiac hypertrophy. Hypertension. 2008;51(5):1345-1351. doi:10.1161/HYPERTENSIONAHA.107.102152. 


\section{FIGURE LEGENDS}

Figure 1: Influence of dietary sodium restriction on cardiac morphological and histological alterations. (2-column fitting image)

A. Systolic tail-cuff pressure in rats fed high fructose diet with a NS $(0.64 \%)$ or LS $(<0.01 \%)$ content, prior to and at the end of the 4-week period of AngII infusion. B. Relative change from pre-AngII period. $\mathrm{N}=20$ in each group. C. Representative microphotographs of hematoxylin-eosin staining of left ventricle tissue and quantitative analysis of cardiomyocyte area. D. The linear relationship between final body and heart weights was determined in all rats. The steepening of the slope observed in AngII, NS fructose rats compared to their controls (7.0x-1.5 vs 3.4x-0.3 HW/kg BW) was prevented in rats fed the LS diet (3.2x-0.1 vs 3.3-0.2 g HW/kg BW for AngII-infused and their LS fructose controls, respectively). N=20 in each group. E. Representative microphotographs of Sirius red staining and quantitative analysis of collagen deposition (\% stained area in left ventricular tissue). $\mathrm{N}=10$ in each group. F. Cardiac expression of TGF- $\beta$ and SMAD2 evaluated by qPCR analysis and expressed relative to GAPDH mRNA. $\mathrm{N}=20$ in each group. $\mathrm{CT}$ : control. Data are means $\pm \mathrm{SEM}$. $* P<0.05$ vs corresponding control group.

Figure 2: Differentially expressed genes. (2-column fitting image)

Histogram showing the 66 differentially expressed genes between NS and LS rats sorted by ontological category "Biological process". Diamonds represent fold enrichment when significant $(\mathrm{P}$ value $<0.05)$.

Figure 3: Infiltration of inflammatory cells in cardiac tissue. (2-column fitting image)

A. Representative microphotographs of immunohistochemistry for CD68 in the left ventricle. Negative controls (NC) are shown in the smaller box. Quantification of CD68 positive 
macrophage infiltration is indicated in the histogram. B. Cardiac mRNA expression of CD68 and CD11b evaluated by qPCR analysis and expressed relative to GAPDH mRNA content. $\mathrm{N}=10$ in each group. C. Cardiac mRNA expression of TNF- $\alpha$, RELA, CCR2 and CCL2 evaluated by qPCR analysis and expressed relative to GAPDH mRNA content. NS and LS group includes control and AngII-infused animals, i.e. 20 rats in each group. Data are means \pm SEM. 
Table 1: Influence of AngII infusion and low sodium diet on experimental parameters in fructose fed rats.

\begin{tabular}{|l|l|l|l|l|}
\hline Groups & $\begin{array}{l}\text { NS Fructose } \\
\text { CT }\end{array}$ & $\begin{array}{l}\text { NS Fructose } \\
+ \text { AngII }\end{array}$ & $\begin{array}{l}\text { LS Fructose } \\
\text { CT }\end{array}$ & $\begin{array}{l}\text { LS Fructose } \\
+ \text { AngII }\end{array}$ \\
\hline Final Body Weight (g) & $420 \pm 8$ & $418 \pm 8$ & $348 \pm 8 \dagger$ & $342 \pm 7 \dagger$ \\
\hline BW Change from week 4 (g) & $56.7 \pm 3.0$ & $60.0 \pm 4.4$ & $38.6 \pm 9.5 \dagger$ & $32.6 \pm 3.3 \dagger$ \\
\hline $\begin{array}{l}\text { 3-day mean food intake (g/24h, } \\
8^{\text {th }} \text { week) }\end{array}$ & $20.3 \pm 0.7$ & $21.6 \pm 0.6$ & $17.8 \pm 0.5 \dagger$ & $18.3 \pm 0.5 \dagger$ \\
\hline Heart Weight (g) & $1.17 \pm 0.04$ & $1.39 \pm 0.04^{*}$ & $0.98 \pm 0.03$ & $1.02 \pm 0.07 \dagger$ \\
\hline Heart Weight Index (mg/gBW) & $2.80 \pm 0.06$ & $3.30 \pm 0.06^{*}$ & $2.78 \pm 0.03$ & $3.00 \pm 0.07 \dagger$ \\
\hline LV Weight (g) & $0.89 \pm 0.03$ & $1.03 \pm 0.03^{*}$ & $0.70 \pm 0.02 \dagger$ & $0.75 \pm 0.03 \dagger$ \\
\hline LV Weight Index (mg/gBW) & $2.05 \pm 0.03$ & $2.48 \pm 0.05^{*}$ & $2.07 \pm 0.04$ & $2.17 \pm 0.05 \dagger$ \\
\hline Plasma glucose, mg/dL & $123 \pm 7$ & $125 \pm 4$ & $127 \pm 4$ & $120 \pm 4$ \\
\hline
\end{tabular}

BW: Body Weight; LV: Left Ventricle. Data are mean $\pm \mathrm{SE}$ ( $\mathrm{n}=20$ per group). ${ }^{*} p<0.05$ vs. the respective control group; $\uparrow \mathrm{p}<0.05$ vs. the corresponding NS Fructose group. 
Table 2: Immune system transcripts that are differentially expressed between NS and LS rats. Microarray and qPCR validation data are shown.

\begin{tabular}{|l|l|l|l|l|l|l|}
\hline \multirow{2}{*}{ Gene symbol } & \multicolumn{5}{|c|}{ Microarray } & \multicolumn{2}{c|}{ qPCR } & \multirow{2}{*}{ NCBI description } \\
\cline { 2 - 6 } & Fold Change & $\mathrm{p}$ value & Corrected $\mathrm{p}$ & Fold Change & $\mathrm{p}$ value & \\
\hline Fcgr3 & $-1,30$ & $2,38 \mathrm{E}-04$ & $9,43 \mathrm{E}-02$ & $-1,35$ & $2,60 \mathrm{E}-03$ & Fc fragment of IgG, low affinity IIa, receptor \\
\hline Fes & $-1,37$ & $3,94 \mathrm{E}-04$ & $9,43 \mathrm{E}-02$ & $-1,17$ & $2,30 \mathrm{E}-02$ & FES proto-oncogene, tyrosine kinase \\
\hline Tlr2 & $-1,39$ & $2,03 \mathrm{E}-04$ & $8,93 \mathrm{E}-02$ & $-1,01$ & $9,17 \mathrm{E}-01$ & Toll-like receptor 2 \\
\hline C1qtnf6 & $-1,40$ & $2,70 \mathrm{E}-04$ & $9,43 \mathrm{E}-02$ & $-1,02$ & $7,68 \mathrm{E}-01$ & C1q and tumor necrosis factor related protein 6 \\
\hline Scarb1 & $-1,43$ & $7,62 \mathrm{E}-05$ & $8,81 \mathrm{E}-02$ & $-1,25$ & $1,44 \mathrm{E}-02$ & Scavenger receptor class B, member 1 \\
\hline Pi16 & $-1,44$ & $1,54 \mathrm{E}-04$ & $8,93 \mathrm{E}-02$ & $-1,24$ & $1,44 \mathrm{E}-02$ & Peptidase inhibitor 16 \\
\hline Tpo & $-1,46$ & $3,62 \mathrm{E}-04$ & $9,43 \mathrm{E}-02$ & 1,13 & $1,65 \mathrm{E}-01$ & Thyroid peroxidase \\
\hline C1qtnf9 & $-1,47$ & $4,30 \mathrm{E}-04$ & $9,43 \mathrm{E}-02$ & $-1,50$ & $3,91 \mathrm{E}-06$ & C1q and tumor necrosis factor related protein 9 \\
\hline Col1a2 & $-1,50$ & $4,13 \mathrm{E}-04$ & $9,43 \mathrm{E}-02$ & $-1,53$ & $2,79 \mathrm{E}-05$ & Collagen, type I, alpha 2 \\
\hline Aif1 & $-1,50$ & $1,22 \mathrm{E}-04$ & $8,81 \mathrm{E}-02$ & $-1,25$ & $1,75 \mathrm{E}-04$ & Allograft inflammatory factor 1 \\
\hline S100a11 & $-1,52$ & $7,35 \mathrm{E}-05$ & $8,81 \mathrm{E}-02$ & $-1,36$ & $4,53 \mathrm{E}-07$ & S100 calcium binding protein A11 \\
\hline Emr1 & $-1,57$ & $1,12 \mathrm{E}-04$ & $8,81 \mathrm{E}-02$ & $-2,34$ & $4,93 \mathrm{E}-05$ & Adhesion G protein-coupled receptor E1 \\
\hline Hamp & $-2,42$ & $4,97 \mathrm{E}-06$ & $5,64 \mathrm{E}-02$ & $-2,86$ & $4,01 \mathrm{E}-07$ & Hepcidin antimicrobial peptide \\
\hline
\end{tabular}


A

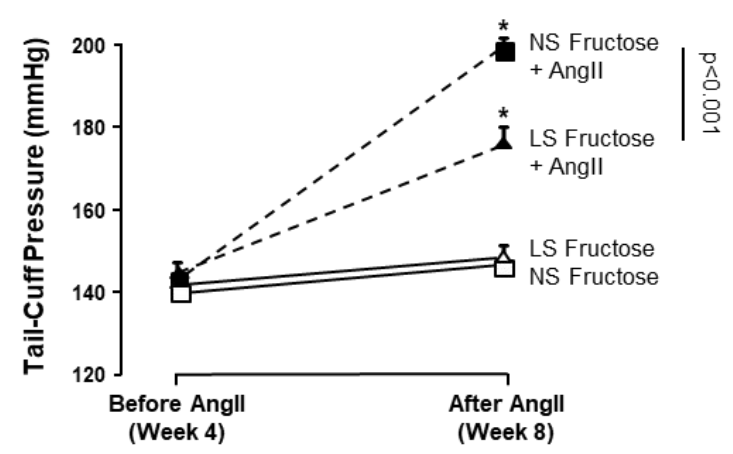

C

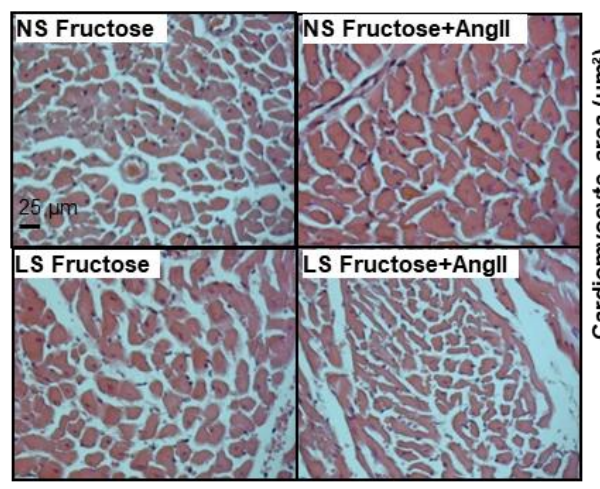

E

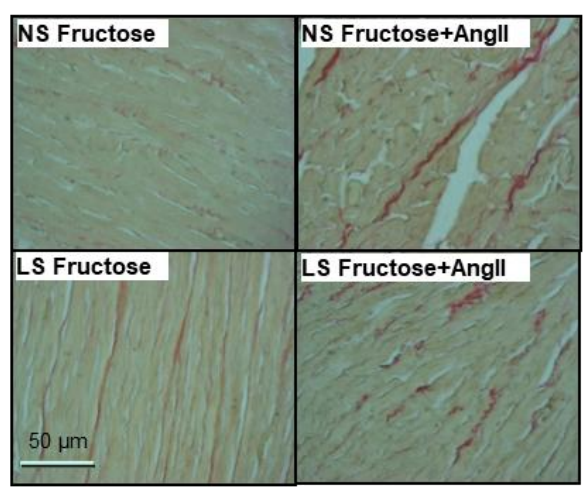

B

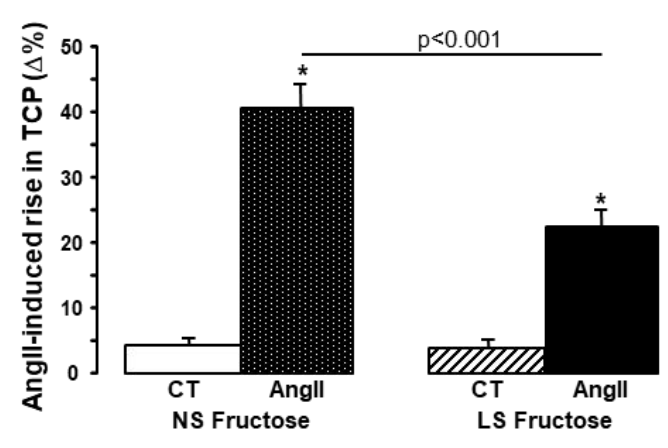

D
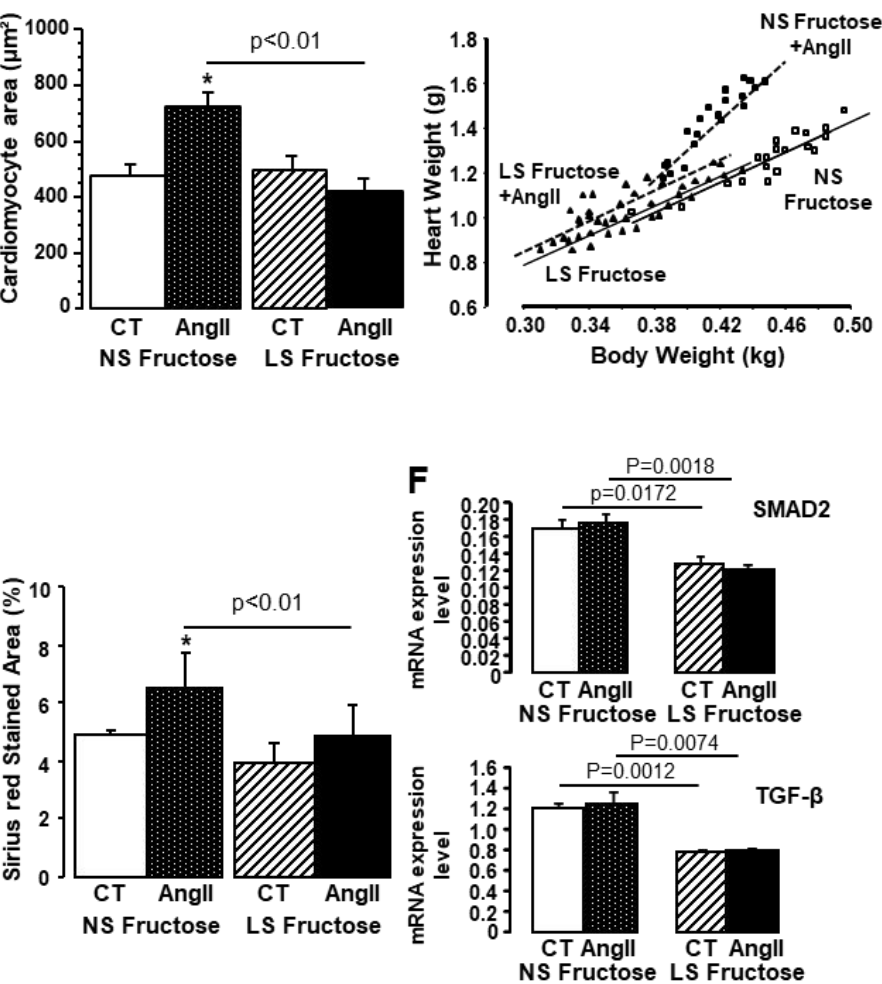

Figure 1: Influence of dietary sodium restriction on cardiac morphological and histological alterations.

A. Systolic tail-cuff pressure in rats fed high fructose diet with a NS $(0.64 \%)$ or LS $(<0.01 \%)$ content, prior to and at the end of the 4-week period of AngII infusion. B. Relative change from pre-AngII period. $\mathrm{N}=20$ in each group. C. Representative microphotographs of hematoxylin-eosin staining of left ventricle tissue and quantitative analysis of cardiomyocyte area. D. The linear relationship between final body and heart weights was determined in all rats. The steepening of the slope observed in AngII, NS fructose rats compared to their controls $(7.0 \mathrm{x}-1.5 \mathrm{vs} 3.4 \mathrm{x}-0.3 \mathrm{HW} / \mathrm{kg} \mathrm{BW})$ was prevented in rats fed the LS diet $(3.2 \mathrm{x}-0.1 \mathrm{vs}$ 3.3-0.2 $\mathrm{g} \mathrm{HW} / \mathrm{kg} \mathrm{BW}$ for AngII-infused and their LS fructose controls, respectively). $\mathrm{N}=20$ in each group. E. Representative microphotographs of Sirius red staining and quantitative analysis of collagen deposition (\% stained area in left ventricular tissue). $\mathrm{N}=10$ in each group. F. Cardiac expression of TGF- $\beta$ and SMAD2 evaluated by qPCR analysis and expressed relative to GAPDH mRNA. $\mathrm{N}=20$ in each group. $\mathrm{CT}$ : control. Data are means $\pm \mathrm{SEM}$. $* P<0.05$ vs corresponding control group. 


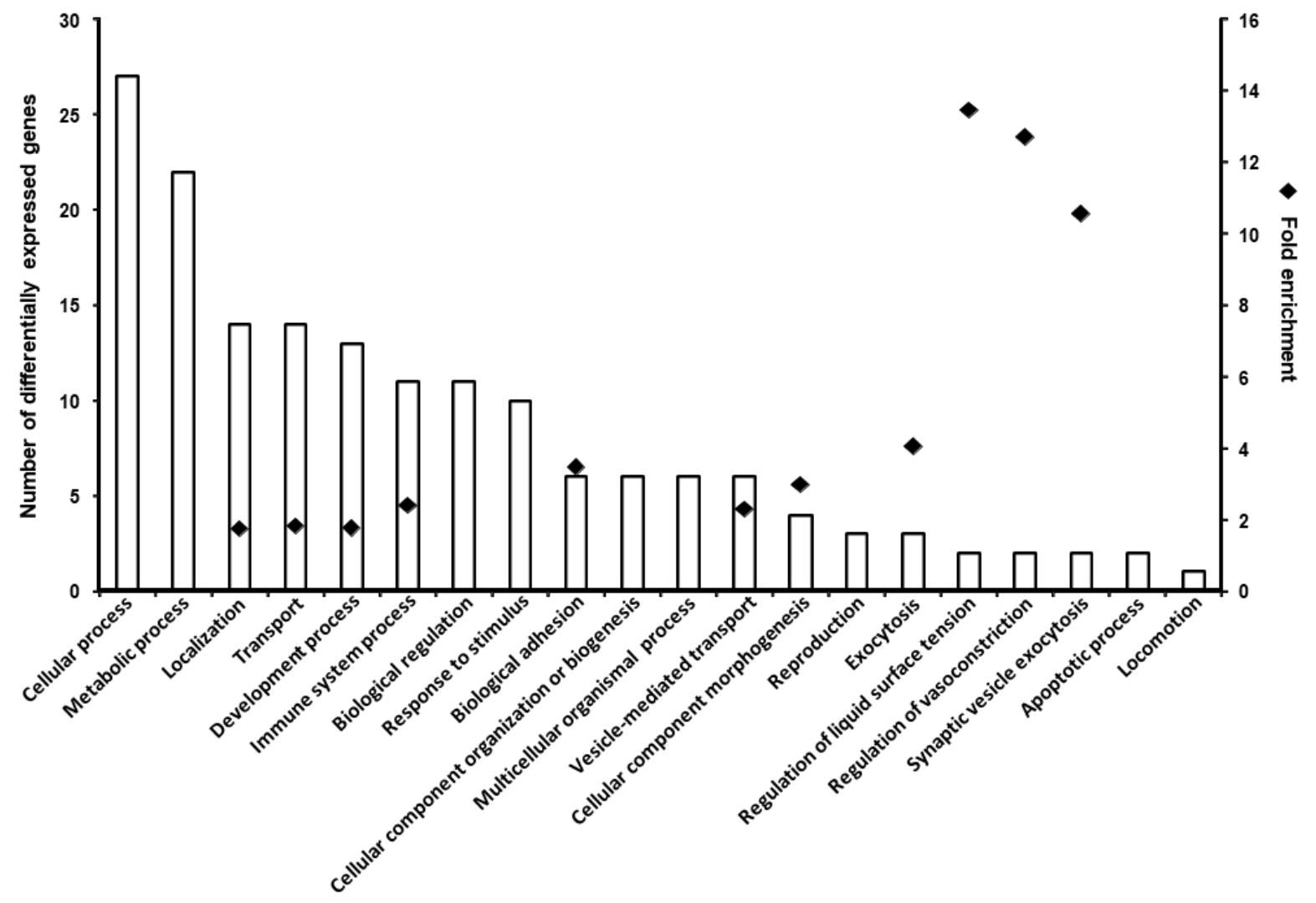

Figure 2: Differentially expressed genes.

Histogram showing the 66 differentially expressed genes between NS and LS rats sorted by ontological category "Biological process". Diamonds represent fold enrichment when significant ( $\mathrm{P}$ value $<0.05$ ). 


\section{A}
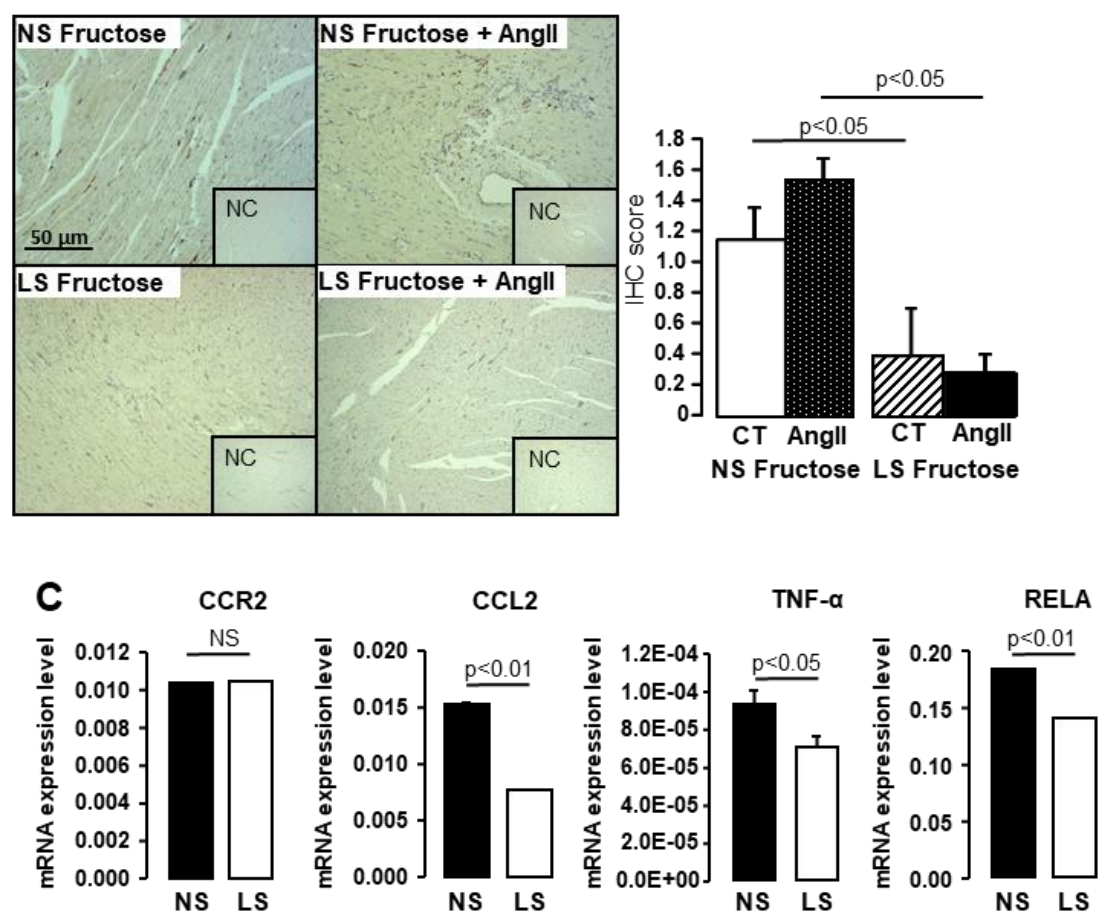
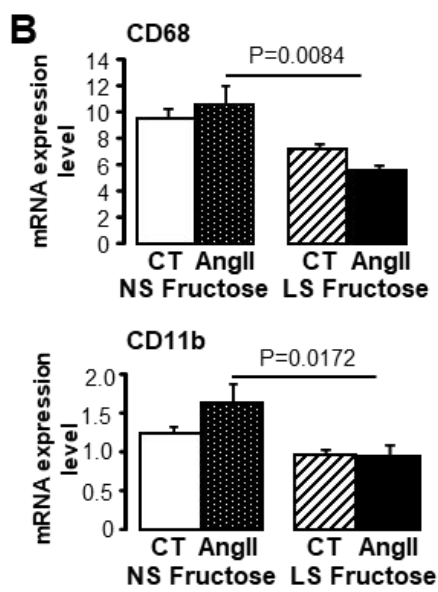

Figure 3: Infiltration of inflammatory cells in cardiac tissue.

A. Representative microphotographs of immunohistochemistry for CD68 in the left ventricle. Negative controls (NC) are shown in the smaller box. Quantification of CD68 positive macrophage infiltration is indicated in the histogram. B. Cardiac mRNA expression of CD68 and CD11b evaluated by qPCR analysis and expressed relative to GAPDH mRNA content. $\mathrm{N}=10$ in each group. C. Cardiac mRNA expression of TNF- $\alpha$, RELA, CCR2 and CCL2 evaluated by qPCR analysis and expressed relative to GAPDH mRNA content. NS and LS group includes control and AngII-infused animals, i.e. 20 rats in each group. Data are means \pm SEM. 


\section{SODIUM RESTRICTION MODULATES INNATE IMMUNITY AND PREVENTS CARDIAC REMODELING IN A RAT MODEL OF METABOLIC SYNDROME}

Bernard Jover $^{\mathrm{a}}$, Christelle Reynes ${ }^{\mathrm{b}, \mathrm{c}}$, Caroline Rugale ${ }^{\mathrm{d}}$, Cyril Reboul ${ }^{\mathrm{e}}$, Laura Jeanson ${ }^{\mathrm{d}}$, Michel Tournier $^{\mathrm{d}}$, Anne Dominique Lajoix ${ }^{\mathrm{d}}$, Caroline Desmetz $^{\mathrm{d}}$

${ }^{a}$ INSERM U1046, CNRS UMR 91214, Montpellier University, Montpellier, France;

${ }^{\mathrm{b}}$ Institute of Functional Genomics, CNRS UMR5203, INSERM U1191, Montpellier University, Montpellier, France

${ }^{c}$ Laboratory of Biostatistics, Informatics and Pharmaceutical Physics, Montpellier University, Montpellier, France

${ }^{\mathrm{d}}$ BioCommunication en CardioMétabolique $\left(\mathrm{BC}^{2} \mathrm{M}\right)$, Montpellier University, Montpellier France

${ }^{\mathrm{e}}$ LaPEC EA4278, Avignon University, Avignon, France

Short Title: Sodium, immunity, cardiac hypertrophy

Correspondence: $\quad$ Bernard Jover, INSERM U1046

IURC, 641 av doyen GIRAUD

34093 Montpellier Cedex 5

Phone: (33) 411759 926; Fax: (33) 411759547

E-mail: bernard.jover@inserm.fr 


\section{METHODS}

The present experiments complied with the European and French laws (permit numbers B3417226 and 34179) and conform to the Guide for the Care and Use of Laboratory Animals published by the National Institute of Health (National Academies Press US, 8th edition, 2011). Rats were housed in climate controlled conditions with a $12 \mathrm{~h}$ light/dark cycle in a room temperature-controlled $\left(22 \pm 1^{\circ} \mathrm{C}\right)$.

\section{Animals and diets.}

Sprague-Dawley rats (Charles River, 180-200g) were fed for 8 weeks $60 \%$ fructose diet with either a normal sodium $(0.64 \% \mathrm{NaCl})$ or a low sodium content $(<0.01 \% \mathrm{NaCl})(\mathrm{n}=40$ in each). Four weeks after the beginning of the $60 \%$ fructose diet, twenty rats from each regimen were infused subcutaneously (osmotic pump Alzet 2004) with angiotensin II (AngII) at the dose of 200 ng. $\mathrm{kg}^{-1} \cdot \mathrm{min}^{-1}$ for the remaining four weeks. The other half was submitted to the same surgery without pump implantation.

\section{Blood pressure and glucose metabolism.}

In all rats, systolic blood pressure was measured in conscious animals using the tail-cuff method (Narco Biosystems INC), prior to and two days before the end of angiotensin II infusion, i.e. at week 4 and 8 of the fructose diet. The day after pressure measurement, rats were fasted (5h) to perform the insulin tolerance test (ITT). Glucose was measured in tail blood before and every 10 minutes for 90 minutes after an injection of lispro insulin $\left(0.6 \mathrm{U} \mathrm{kg}^{-}\right.$ ${ }^{1}$ intraperitoneal, Humalog, Lilly). Results are shown in supplementary data, figure S1.

At the end of the experiment ( 8 weeks), rats were anaesthetized (pentobarbital, $60 \mathrm{mg} \mathrm{kg}^{-1}, \mathrm{IP}$ ) and the heart was excised and rinsed. Large vessels and surrounding epicardial fat were carefully removed. The left ventricle (LV) including septum was weighed separately. Heart 
and LV weight to body weight ratios were calculated as index of cardiac (HWI) and LV (LVWI) hypertrophy respectively.

\section{Cardiac histology and morphology.}

Half of the 20 rats from the four experimental groups served for cardiac histological and morphological determination. The LV was paraffin embedded, and 3-5 $\mu \mathrm{m}$ slices were cut for histological analysis. After haematoxylin-eosin coloration, the cardiomyocyte size was determined through measurement of the shortest transverse diameter in 30 transverse sections per heart. Collagen volume fraction was determined after by Sirius red staining, as previously described ${ }^{1}$. CD68 staining was used as a marker of rat macrophages and determined in LV tissues, as previously described ${ }^{2}$.

\section{RNA extraction, Microarray and statistical data analysis}

Microarray analysis was performed on cardiac tissue of twelve rats on the NS and LS fructose diets ( $n=6$ in each), three animals taken in both control and AngII groups. Immediately after anaesthesia, the heart was collected, cleaned and weighed, and left ventricle samples were frozen in RNAlater ${ }^{\circledR}$ solution (Life Technologies). Tissues were then dissociated in RLT buffer using a Fast-Prep ${ }^{\circledR}$ homogeneizer (MP Biomedicals). Total RNA was extracted using RNeasy® Fibrous Tissue mini-kit (Qiagen). RNA quality and integrity were determined using the Agilent 2100 Bioanalyser (Agilent Technologies).

For microarray experiments, sample treatment was performed as described using "one color microarray-based gene expression analysis" protocol (version 6.7, part number G414090040). Briefly, 200ng of each total RNA samples $(\mathrm{N}=12)$ was used for amplification and labelling with the Agilent Low Input Quick amp Labelling kit, one color. Yields of cRNA and dye incorporation rate were measured using ND-1000 spectrometer (NanoDrop technologies, 
Peqlab biotechnologies GmbH, Erlangen, Germany). Hybridization procedure was performed using Agilent Gene Expression Hybridization kit. Briefly, 1.65 $\mu \mathrm{g}$ Cy3-labeled fragmented cRNA was hybridized $17 \mathrm{~h}$ at $65^{\circ} \mathrm{C}$ to Agilent Rat Gene Expression Microarray V3 $4 x 44 \mathrm{~K}$ using recommended manufacturer's hybridization chambers and oven. The microarrays were then washed once with the Agilent Gene Expression Wash Buffer for 1 min at RT, and then washed with Agilent Gene Expression Wash buffer 2 at $37^{\circ} \mathrm{C}$ for $1 \mathrm{~min}$.

Fluorescence signals were detected using Agilent's Microarray Scanner System and the Agilent Feature Extraction Software (version 11.0.1.1) to read out and process the microarray image files.

The microarray data have been deposited in NCBI's Gene Expression Omnibus ${ }^{3}$ and are accessible through GEO series accession number GSE84524.

Statistical analysis was performed using $\mathrm{R}$ software version $3.3 .0^{4}$ along with the Limma package $^{5}$. The method used for background correction was based on the normal-exponential convolution model with the saddle-point approximation to maximum likelihood ${ }^{6}$. Normalization was performed using cyclic loess ${ }^{7}$ method. Only probes whose signal was considered as higher than background in at least four out of six replicates in at least one condition were selected for further analysis. Within-array replicate probes were replaced with their average. The assessment of differentially expressed mRNAs between NS diet and LS diet was performed using the limma GLM (Generalized Linear Model) method followed by Benjamini Hochberg correction for multiple testing. Genes with a corrected p-value lower than 0.1 were selected for further investigation.

\section{Gene Ontology (GO) enrichment analysis}

The genes symbols of significantly differentially expressed genes were matched with GO terms using gene annotations for the organism Rattus norvegicus in terms of biological 
process, molecular function and cellular component (www.geneontology.org). GO terms enrichment analysis of these genes was performed. To this end, a binomial test was applied to determine whether there is a statistical overrepresentation or underrepresentation of the genes in our test list relative to the reference list (rat genome). A P value was calculated to determine whether the over- or underrepresentation is significant or not $(\mathrm{p}<0.05$ considered significant $)^{8}$.

RNA isolation, reverse transcription, and real-time quantitative PCR analysis.

The second half $(\mathrm{N}=10)$ of rats from each group was used for transcript analysis. Immediately after anaesthesia, the heart was collected, cleaned and weighed, and left ventricle samples were frozen in RNAlater ${ }^{\circledR}$ solution (Life Technologies). Tissues were then dissociated in RLT buffer using a Fast-Prep® homogeneizer (MP Biomedicals). Total RNA was extracted using RNeasy® Fibrous Tissue mini-kit (Qiagen). Complementary DNA was synthesized using Omniscript ${ }^{\circledR}$ reverse transcriptase (Life Technologies). Real-time quantitative PCR was done with the use of the LC480 real time PCR instrument (Roche). Primer pairs were generated using NCBI primer design application and were designed to span an exon-exon junction. Forward and reverse primers sequences are shown in table $\mathrm{S} 1$ and were used at a $60^{\circ} \mathrm{C}$ annealing temperature. Data on gene expression were normalized according to data from Gapdh housekeeping gene.

\section{Western Blotting}

Snap frozen left ventricles from fructose+AngII NS $(n=3)$ and LS $(n=3)$ rats were dissociated in RIPA buffer (Abcam) using a Fast-Prep ${ }^{\circledR}$ homogeneizer (MP Biomedicals). Total proteins were quantified using BCA assay (Pierce). Western blotting was performed using antibodies as follows: anti-AIF-1 (Abcam, ab178847), anti-Hepcidin-25 (Abcam, ab187778), anti- 
S100A11 (Abcam, ab180593), anti-GAPDH (Santa Cruz, sc-25778). The secondary antibody was an anti-rabbit antibody from Millipore (AP188P).

\section{Statistical analysis.}

Quantitative PCR results are expressed as the mean \pm SEM. The statistical evaluation was performed using two-factor analysis of variance (ANOVA) and post hoc comparisons were performed by means of Fisher's Protected Least Significant Differences (PLSD) test. If the data were not normally distributed, statistical evaluation was performed by using ANOVA (Kruskall-Wallis) and Mann-Whitney U test. Differences were considered significant when $\mathrm{p}<0.05$.

1. Cordaillat M, Rugale C, Casellas D, Mimran A, Jover B. Cardiorenal abnormalities associated with high sodium intake: correction by spironolactone in rats. American Journal of Physiology. Regulatory, Integrative and Comparative Physiology. 2005;289(4):R1137-1143.

2. Oudot C, Lajoix AD, Jover B, Rugale C. Dietary sodium restriction prevents kidney damage in high fructose-fed rats. Kidney International. 2013;83(4):674-683.

3. Edgar R, Domrachev M, Lash AE. Gene Expression Omnibus: NCBI gene expression and hybridization array data repository. Nucleic Acids Res. 2002 Jan 1;30(1):207-10.

4. R Core Team (2013). R: A language and environment for statistical computing. R Foundation for Statistical Computing, Vienna, Austria. URL http://www.R-project.org/.

5. Ritchie, ME, Phipson, B, Wu, D, Hu, Y, Law, CW, Shi, W, and Smyth, GK (2015). 
Limma powers differential expression analyses for RNA-sequencing and microarray studies. Nucleic Acids Research 43(7), e47.

6. Silver, J. D., Ritchie, M. E., \& Smyth, G. K. (2009). Microarray background correction: maximum likelihood estimation for the normal-exponential convolution. Biostatistics, 10, $352-363$.

7. Boldstad, B. M., Irizarry, R. A., Astrand, M., \& Speed, T. P. (2003). A comparison of normalization methods for high density oligonucleotide array data based on bias and variance. Bioinformatics, 19(2), 185-193.

8. Mi H, Muruganujan A, Casagrande JT, Thomas PD (2013). Large-scale gene function analysis with the PANTHER classification system. Nat Protocols Aug;8(8):1551-66. 
Table S1: primer pairs used for qPCR

\begin{tabular}{|c|c|c|}
\hline Name & Forward primer & Reverse primer \\
\hline EMR1 & 5'-GCCATAGCCACCTTCCTGTT-3' & 5'ATAGCGCAAGCTGTCTGGTT-3' \\
\hline S100A11 & 5'-CATCGAGTCCCTGATTGCTGT-3' & 5'-GGGTCCTTCTGGTTCTTCGTG-3' \\
\hline TLR2 & 5'-GAGGTCTCCAGGTCAAATCTCAG-3' & 5'-ACACACCAGCAGCATCACAT-3' \\
\hline TLR4 & 5'-CTCTGCCCTGCCACCATTTA-3' & 5'-AGGAAGTACCTCTATGCAGGGAT-3' \\
\hline FES & 5'-GCCAGCAAAGACAAGGATCG-3' & 5'-AGTACGTAGCGGTTGTGGTG-3' \\
\hline PI16 & 5'-AGAGAATCGGCTGTGGTTCC-3' & 5'-GGTTTTCTCTCCGGCTCACA-3' \\
\hline TPO & 5'-TCCACGGATGCACTATCAGC-3' & 5'-TTGCTAGGGCTGTGTTGGAG-3' \\
\hline AIF1 & 5'-TCATCGTCATCTCCCCACCT-3' & 5'-GCTTTTCCTCCCTGCAAATCC-3' \\
\hline SCARB1 & 5'-AGGTGCTCAAGAATGTCCGC-3' & 5'-CATTTAGGACCTCGCTGGGG-3' \\
\hline C1QTNF6 & 5'-TCCTCTTGTGTTTGGGGTCC-3' & 5'-CCCTTTGTCACCTTTCAGGATG-3' \\
\hline C1QTNF9 & 5'-AGACACAGGAGAACCAGGACAT-3' & 5'-ACCTCGCCTTTATCCCCCTT-3' \\
\hline FCGR2A & 5'-CTGAAGGGCTCCGGTTCG-3' & 5'-GTCTAGGAGATGAACTGCTGGC-3' \\
\hline HAMP & 5'-AGATGGCACTAAGCACTCGG-3' & 5'-CCGTAGTCTGTCTCGTCTGTT-3' \\
\hline COL1A2 & 5'-TGTCGATGGCTGCTCCAAAA-3' & 5'-CCGATGTCCAGAGGTGCAAT-3' \\
\hline RAGE & 5'-TTCCTGATGGCAAAGGGACA-3' & 5'-CTGACCGAAGCGTGAAGAGT-3' \\
\hline CD68 & 5'-CGCATCTTGTACCTGACCCA-3' & 5'-AGAATGTCCACTGTGCTGCTT-3' \\
\hline CD11b & 5'-TTGCCTAGGGGGAGAGCAC- 3' & 5'-GCTGGCTACTGATGCTCCAT- 3' \\
\hline TNF- $\alpha$ & 5'-GTAGCCCACGTCGTAGCAAA-3' & 5'-AAATGGCAAATCGGCTGACG-3' \\
\hline RELA & 5'-CATACGCTGACCCTAGCCTG-3' & 5'-CGGGGTTCAGTTGGTCCATT-3' \\
\hline CCL2 & 5'-TGTCTCAGCCAGATGCAGTT-3' & 5'-CAGCCGACTCATTGGGATCA-3' \\
\hline CCR2 & 5'-TAGGGCTGTGAGGCTCATCT-3' & 5'-GCTCCCCAGTAGAAGGGGTA-3' \\
\hline TGF- $\beta$ & 5'-CTGGAAAGGGCTCAACACCT-3' & 5'-CTTCTCTGTGGAGCTGAAGCA-3' \\
\hline SMAD2 & 5'-TCCATCTTGCCATTCACTCCG-3' & 5'-GAGCAAGTGCTTGGTATGGTGA-3' \\
\hline GP91PHOX & 5'-AGACTGGACTGAGGGGCTAT-3' & 5'-CAGGTCTGCGAACCACTCAA-3' \\
\hline GAPDH & 5'-ACTTTGGCATCGTGGAAGGG-3' & 5'ACTTGGCAGGTTTCTCCAGG-3' \\
\hline
\end{tabular}




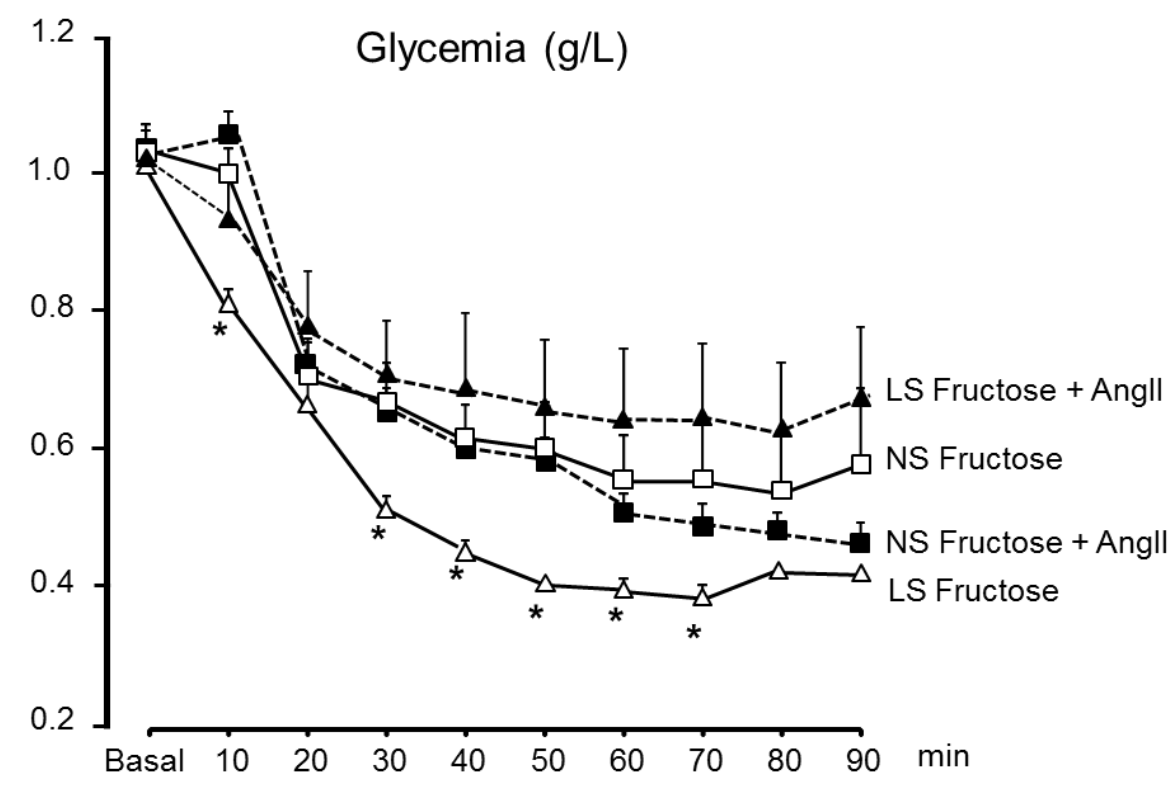

AUC (g glucose/10min)

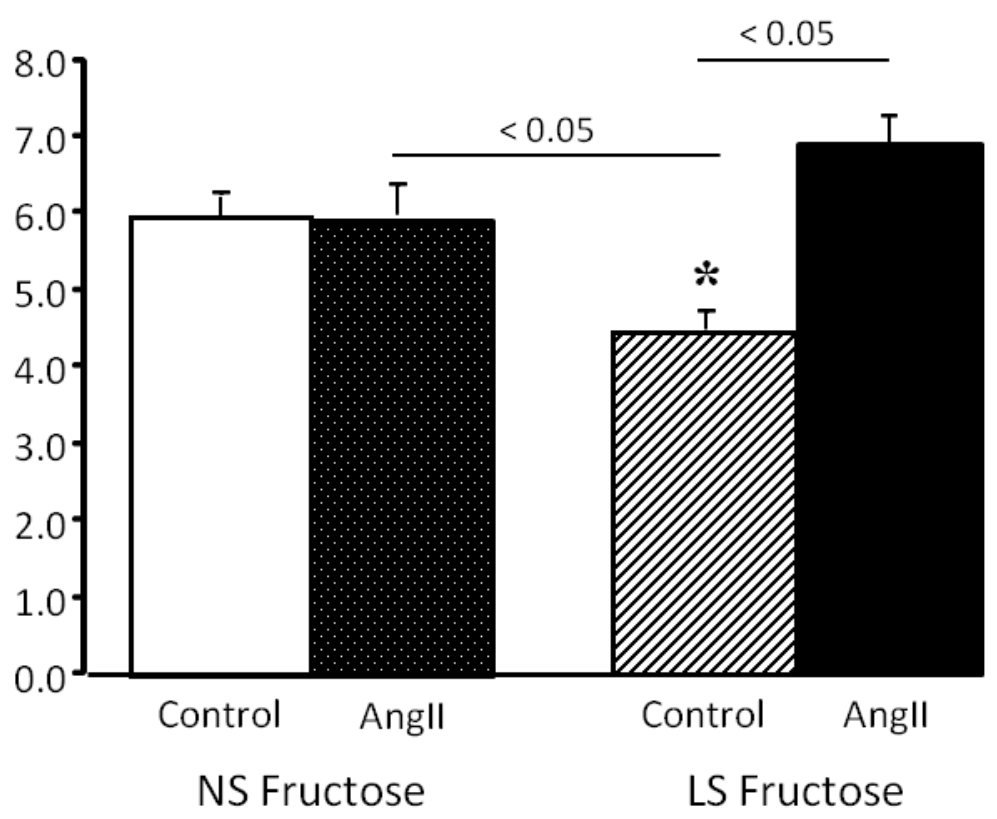

Figure S1: Insulin sensitivity in rats fed high fructose diet with a normal sodium (NS $0.64 \%$ ) or low sodium (LS<0.01\%) content. A: Change in glycaemia during the insulin tolerance test at the end of the 4-week period of angiotensin II infusion. B: Area under the curve (AUC) of glycaemia response during the insulin tolerance test (ITT). $\mathrm{N}=20$ in each group. Data are means \pm SEM. $* P<0.05$ compared to the NS Fructose control group. 

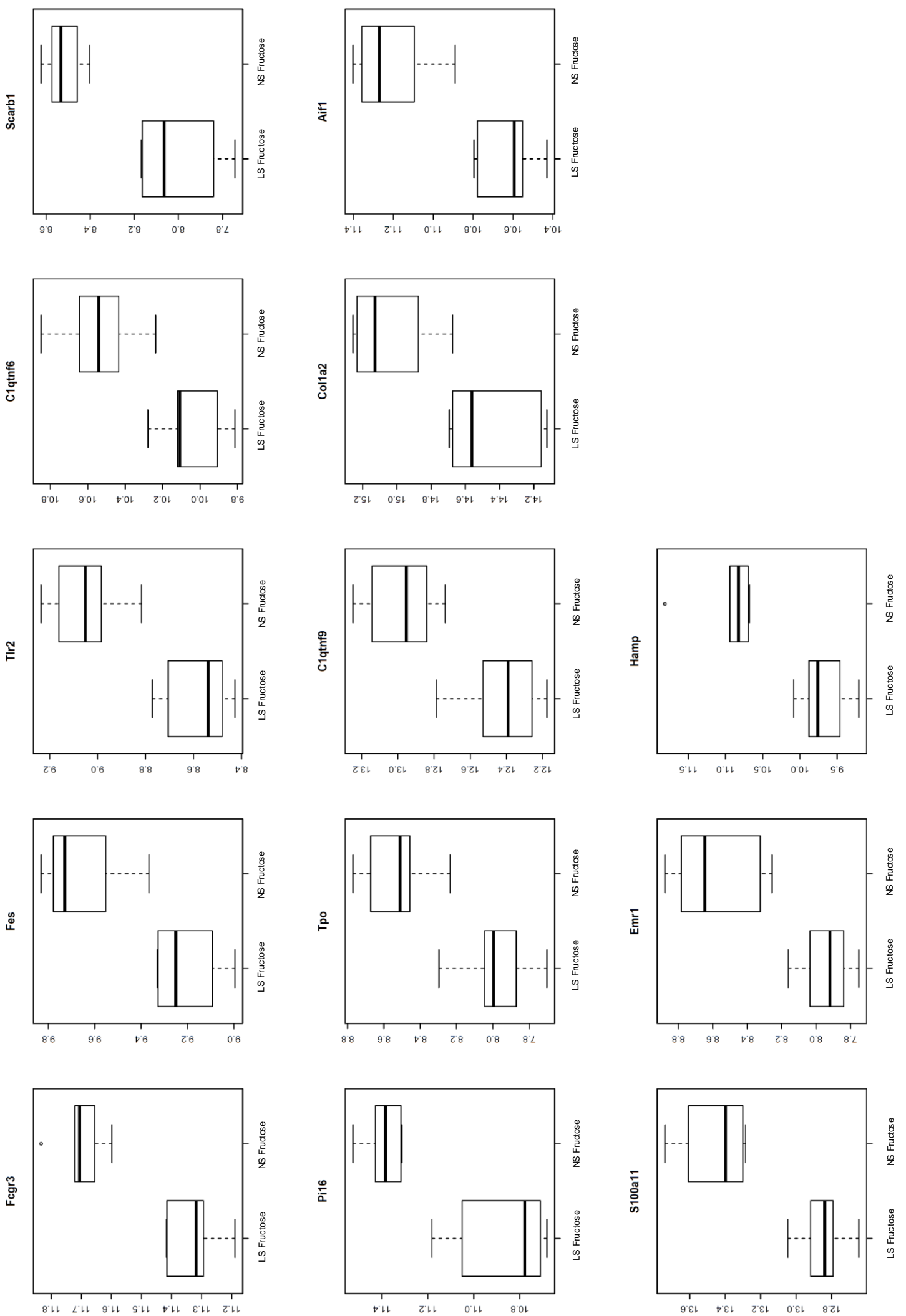

Figure S2: Boxplot of differentially expressed genes involved in immunological process. (Fcgr3=Fcgr2a) 


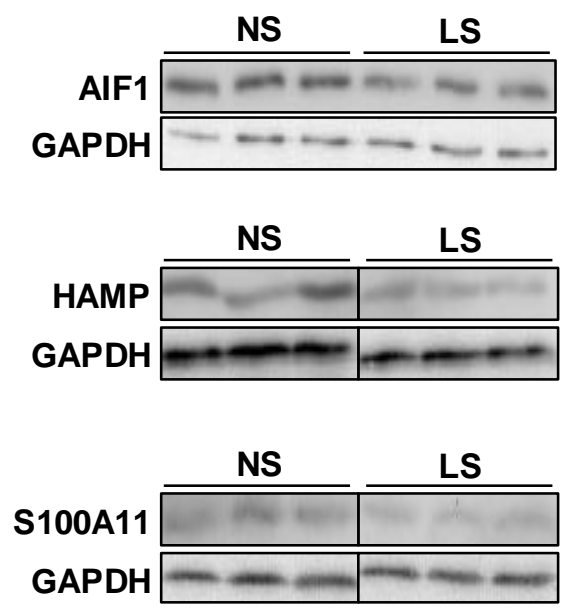

Figure S3: Cardiac expression of AIF1, HAMP and S100A11 by immunoblot. GAPDH expression was used as a control. 


\section{S100A11}

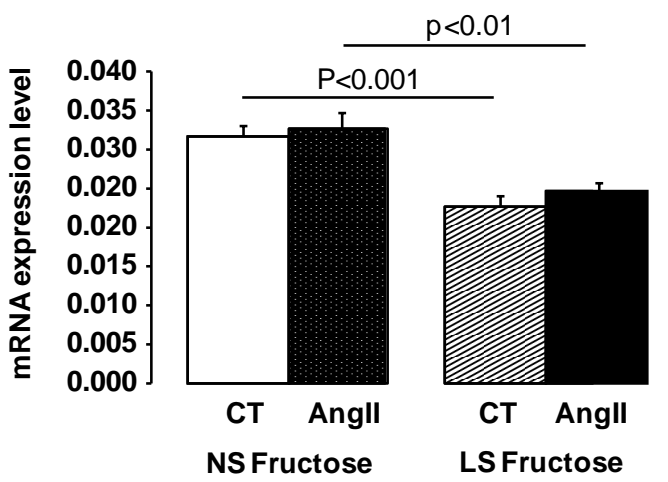

\section{RAGE}

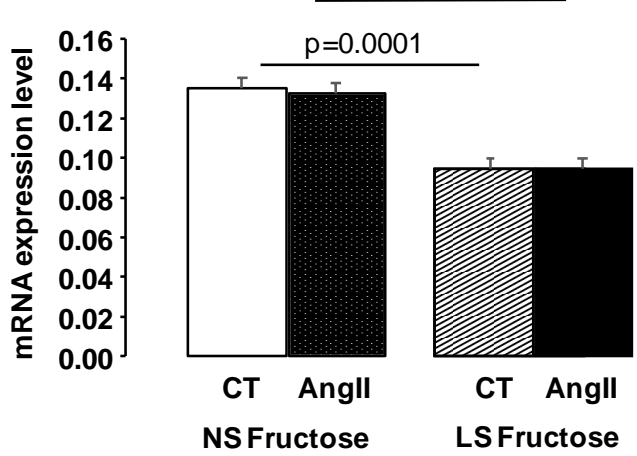

Figure S4: Cardiac mRNA expression of S100A11 and RAGE evaluated by qPCR. Data are mean \pm SEM. 


\section{gp91phox}

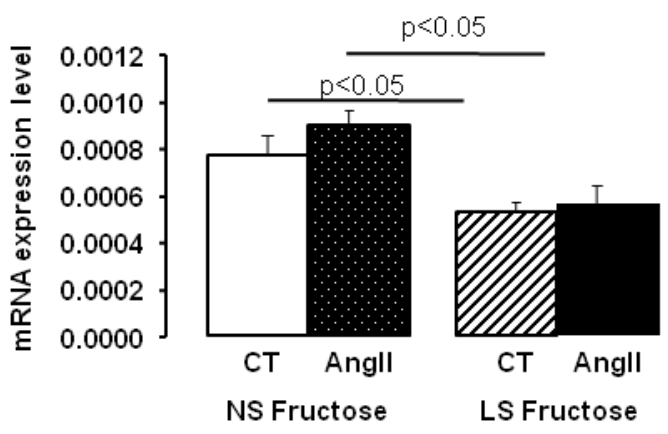

\section{TLR4}

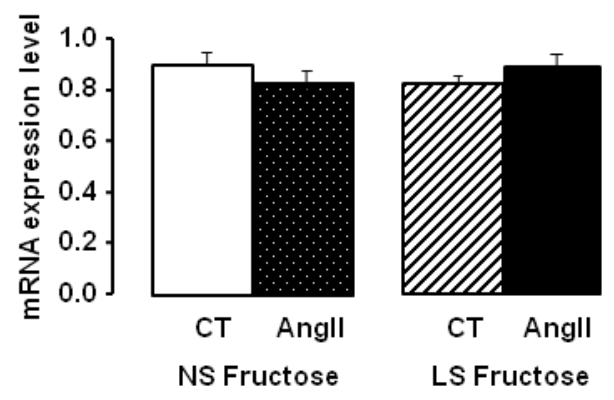

Figure S5: Cardiac mRNA expression of TLR4 evaluated by qPCR. Data are mean \pm SEM. 


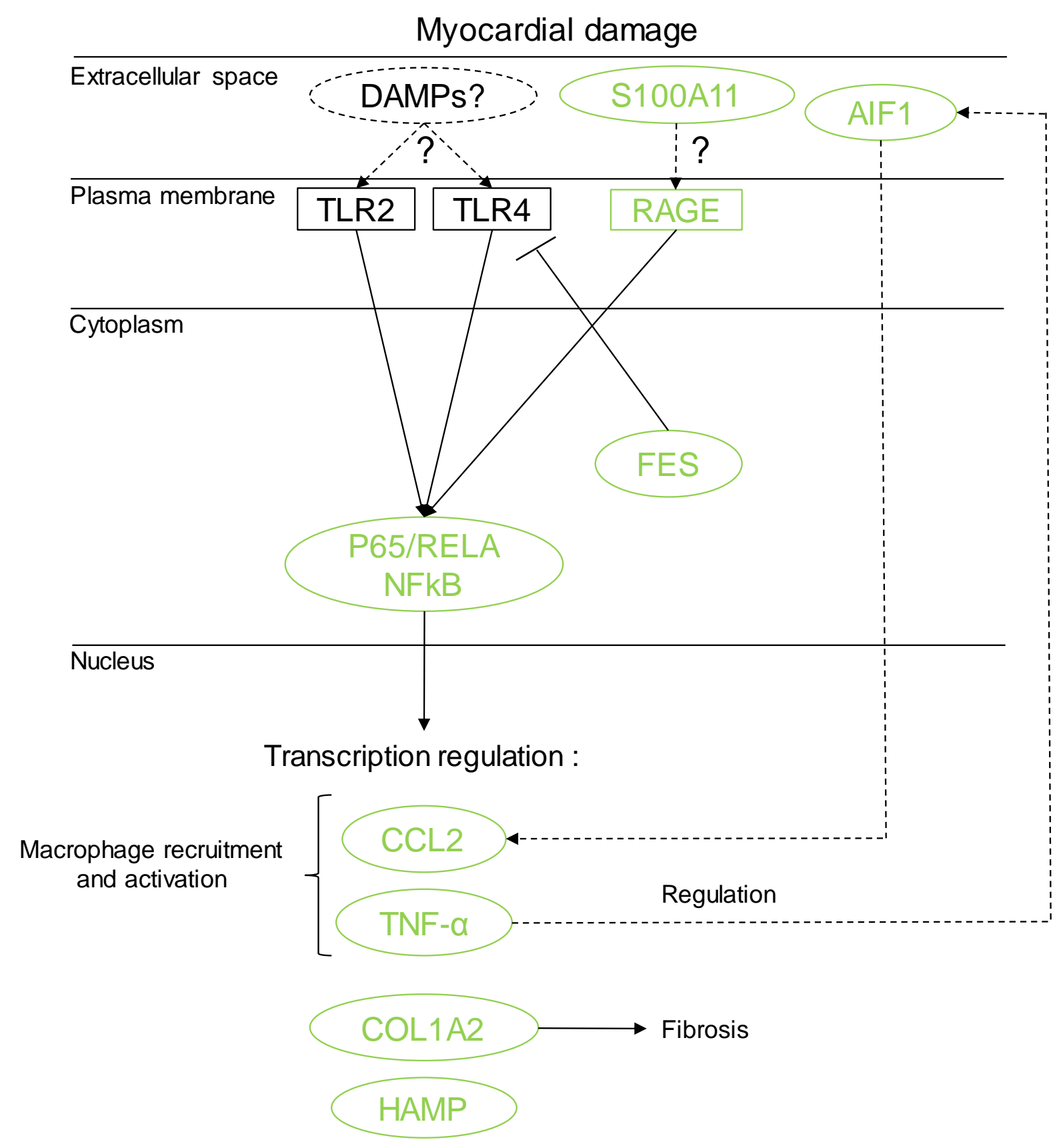

Green Downregulated in LS diet

Black Unchanged in LS diet

$\rightarrow$ Documented action

Possible action

Figure S6: Network depicting gene products differentially regulated in the heart of rats in our model of metabolic syndrome. Documented and possible relationships between them are indicated. 